\title{
David valve-sparing aortic root replacement: Equivalent mid-term outcome for different valve types with or without connective tissue disorder
}

\author{
John-Peder Escobar Kvitting, MD, PhD, ${ }^{\text {a }}$ Fabian A. Kari, MD, ${ }^{a}$ Michael P. Fischbein, MD, PhD, ${ }^{a}$ \\ David H. Liang, MD, PhD, ${ }^{b}$ Anne-Sophie Beraud, MD, ${ }^{b}$ Elizabeth H. Stephens, MD, PhD, ${ }^{a}$ \\ R. Scott Mitchell, MD, ${ }^{a}$ and D. Craig Miller, MD $^{\mathrm{a}}$
}

Objective: Although implicitly accepted by many that the durability of valve-sparing aortic root replacement in patients with bicuspid aortic valve disease and connective tissue disorders will be inferior, this hypothesis has not been rigorously investigated.

Methods: From 1993 to 2009, 233 patients (27\% bicuspid aortic valve, 40\% Marfan syndrome) underwent Tirone David valve-sparing aortic root replacement. Follow-up averaged $4.7 \pm 3.3$ years (1102 patientyears). Freedom from adverse outcomes was determined using log-rank calculations.

Results: Survival at 5 and 10 years was $98.7 \% \pm 0.7 \%$ and $93.5 \% \pm 5.1 \%$, respectively. Freedom from reoperation (all causes) on the aortic root was $92.2 \% \pm 3.6 \%$ at 10 years; 3 reoperations were aortic valve replacement owing to structural valve deterioration. Freedom from structural valve deterioration at 10 years was $96.1 \%$ $\pm 2.1 \%$. No significant differences were found in survival $(P=.805, P=.793$, respectively), reoperation $(P=.179, P=.973$, respectively), structural valve deterioration $(P=.639, P=.982$, respectively $)$, or any other functional or clinical endpoints when patients were stratified by valve type (tricuspid aortic valve vs bicuspid aortic valve) or associated connective tissue disorder. At the latest echocardiographic follow-up (95\% complete), 202 patients $(94.8 \%)$ had none or trace aortic regurgitation, $10(4.7 \%)$ mild, 0 had moderate to severe, and $1(0.5 \%)$ had severe aortic regurgitation. Freedom from greater than $2+$ aortic regurgitation at 10 years was $95.3 \% \pm 2.5 \%$. Six patients sustained acute type B aortic dissection (freedom at 10 years, $90.4 \% \pm 5.0 \%$ ).

Conclusions: Tirone David reimplantation valve-sparing aortic root replacement in carefully selected young patients was associated with excellent clinical and echocardiographic outcome in patients with either a tricuspid aortic valve or bicuspid aortic valve. No demonstrable adverse influence was found for Marfan syndrome or connective tissue disorder on durability, clinical outcome, or echocardiographic results. (J Thorac Cardiovasc Surg 2013; 145:117-27)

\section{Supplemental material is available online.}

The surgical management of aortic valve regurgitation and aortic root pathology has evolved during the past 3 decades. ${ }^{1}$ The standard of care using composite valve grafts (CVG) with a mechanical or bioprosthetic valve has several

\footnotetext{
From the Department of Cardiovascular and Thoracic Surgery, ${ }^{a}$ and Division of Cardiovascular Medicine, ${ }^{\mathrm{b}}$ Stanford University School of Medicine, Stanford, Calif.

This work was supported by the US-Norway Fulbright Foundation, the Swedish Heart-Lung Foundation, and the Swedish Society for Medical Research (to Dr Kvitting).

Disclosures: Authors have nothing to disclose with regard to commercial support. Read at the 92nd Annual Meeting of The American Association for Thoracic Surgery, San Francisco, California, April 28-May 2, 2012.

Received for publication April 23, 2012; revisions received Aug 13, 2012; accepted for publication Sept 12, 2012; available ahead of print Oct 19, 2012.

Address for reprints: D. Craig Miller, MD, Department of Cardiovascular and Thoracic Surgery, Falk Cardiovascular Research Center, Stanford University School of Medicine, Stanford, CA 94305-5247 (E-mail: dcm@stanford.edu). $0022-5223 / \$ 36.00$

Copyright (c) 2013 by The American Association for Thoracic Surgery http://dx.doi.org/10.1016/j.jtcvs.2012.09.013
}

important—but different—inherent limitations (eg, indefinite need for anticoagulation versus limited durability, respectively). Based on the premise that preserving the patient's native aortic valve would be associated with a substantially lower incidence of all valve-related complications, several surgical techniques have been described and are generically termed "valve-sparing aortic root replacement" (V-SARR). ${ }^{2,3}$

V-SARR has been proposed as a reasonable treatment alternative for patients with connective tissue disorders (CTDs) such as Marfan syndrome (MFS) and bicuspid aortic valve (BAV) disease. However, several groups have observed high reoperation rates in both patients with MFS and BAV and raised concern about the use of V-SARR in such patients. $^{4-8}$ Thus, the widespread use of V-SARR in patients with BAV or CTD remains controversial, especially when a reproducible and durable alternative exists such as CVG with a mechanical valve., 90 Furthermore, the reoperation risks remain undetermined whether reoperation after V-SARR should become necessary, but the reoperation mortality rate after other 


$$
\begin{aligned}
& \text { Abbreviations and Acronyms } \\
& \begin{aligned}
\text { BAV } & =\text { bicuspid aortic valve } \\
\text { CTD } & =\text { connective tissue disorder } \\
\text { CVG } & =\text { composite valve graft } \\
\text { MFS } & =\text { Marfan syndrome } \\
\text { V-SARR } & =\text { valve-sparing aortic root replacement } \\
\text { TAV } & =\text { tricuspid aortic valve } \\
\text { TTE } & =\text { transthoracic echocardiogram }
\end{aligned}
\end{aligned}
$$

types of aortic root replacement procedures has been reported to exceed $11 \%$. $^{11}$

Hence, we compared the midterm survival, risk of reoperation, incidence of structural valve deterioration, and degree of residual aortic regurgitation (AR) in patients with either a tricuspid aortic valve (TAV) or BAV with or without CTD using the Tirone David reimplantation technique of V-SARR.

\section{METHODS \\ Patients}

A Tirone David-I, Tirone David-V, or Tirone David-V-Stanford modification V-SARR was performed in 233 patients at Stanford from July 1993 to December 2009 (total number at Stanford now > 300) with the follow-up window closing in June 2010. One patient undergoing root repeat replacement after a previous Yacoub remodeling procedure for acute aortic dissection was excluded. A total of 170 patients $(73 \%)$ had a TAV and $63(27 \%)$ a BAV. The mean age was $36 \pm 13$ years (range, 11-68) for the TAV group and $43 \pm 12$ years (range, 19-64) for the BAV group; $115(67 \%)$ and 50 $(80 \%)$ were male patients in the TAV and BAV groups, respectively. No patient required an emergency procedure for acute type A aortic dissection. Additional demographic variables according to valve type are listed in Table 1 . The distribution of patients by valve type over time is illustrated in Figure 1, A. The age distribution of the TAV and BAV patients and BAV subtypes according to Sievers' classification ${ }^{12}$ are shown in Figure 1, $B$ and $C$, respectively. The patients in the TAV group were significantly younger, taller, and slimmer than in the BAV group (Table 1). While the TAV group had larger aortic root dimensions, the BAV group had larger ascending aortic diameters.

\section{Operative Procedure}

Early in the experience, the original V-SARR reimplantation technique described by David and Feindel (Tirone David-I) was used in 26 patients. ${ }^{3}$ Thereafter, 19 patients received a Tirone David-V procedure. The Tirone David-V-Stanford modification V-SARR technique has been used exclusively since December 2002 in 188 patients. ${ }^{13}$

Total or partial transverse arch replacement was performed when necessary using the "Peninsula technique," with a single sigmoid-shaped suture line from the ligamentum to the innominate artery using selective antegrade cerebral perfusion (usually a 6-8 $\mathrm{mm}$ arterial perfusion graft sewn to the innominate artery; a distribution of cannulation sites is given in Table 2) and moderate hypothermic circulatory arrest (bladder $25^{\circ} \mathrm{C}$ $\left.27^{\circ} \mathrm{C}\right) .{ }^{14}$ Concomitant arch replacement was performed more frequently in patients with a BAV because their aneurysmal pathologic features often included the $\operatorname{arch}^{15}$ (Figure 1,D).

Coronary artery reimplantation as full-thickness Carrel "button" anastomoses was done whenever possible. One patient with an anomalous, intramural coronary artery had his left main coronary artery reconstructed using an arterial (superficial femoral) autograft. Six patients required a Kay-Zubiate right coronary reconstruction (2-3-cm greater saphenous vein interposition graft) because of technical complications. The distribution and type of aortic valve repairs used in the TAV and BAV group and concomitant procedures are listed in Table 2.

\section{Valve Repair}

Aortic valve cusp repair was performed in 63 of the TAV patients (37\%). Cusp repair consisted of shortening the free margin at the nodulus of Arantius in all $63 \mathrm{TAV}$ patients without formal cusp plication sutures. Among the BAV patients, 42 required cusp-free margin shortening $(67 \%)$ using 1 or more sutures to correct prolapse and cusp redundancy. A total of 68 sutures were placed, resulting in an average of about 1.4 sutures (range, 1-4) per patient. Seven of these sutures were centrally placed at the nodulus of Arantius, and the remaining 61 sutures were placed further toward the commissures along the cusp-free margin. In addition, a small triangular resection of the raphé was performed in 7 BAV patients, along with cusp-free margin shortening. Creation of commissural neosuspensory cords using 5-0 Gore-Tex sutures was done in $3 \mathrm{BAV}$ patients to replace ruptured "truncal" commissural suspensory chords.

\section{Endpoints}

The primary endpoints were all-cause overall mortality; reoperation on the aortic root for any cause; structural valve deterioration (SVD); and freedom from greater than $2+\mathrm{AR}$.

\section{Follow-up}

Postoperative valve-related adverse events were compiled and analyzed according to the American Association for Thoracic Surgery-Society of Thoracic Surgeons-European Association Cardio-Thoracic Surgery Guidelines for Reporting Morbidity and Mortality after Cardiac Valvular Operations. ${ }^{16}$ The patients were followed up clinically on a regular basis; current follow-up data were obtained by interviewing the patients and their physicians by telephone. The mean \pm standard deviation follow-up was 4.7 \pm 3.3 years; the maximum follow-up was 15.1 years (median, 4.2 years; interquartile range, 2.3-6.6 years; cumulative, 1102 patient-years). At 5 years of follow-up, 88 patients remained at risk, but only 18 patients were at risk at 10 years; for those with MFS or other CTD, the corresponding numbers were 46 and 7 . SVD was categorized according to the valvereporting guidelines. ${ }^{16}$

\section{Echocardiography}

Transthoracic echocardiograms (TTEs) were performed periodically (usually once annually) postoperatively. We obtained late TTE images in 213 of 224 patients (233 minus 4 deaths and 5 who underwent late AVR), equating to $95 \%$ late echocardiographic follow-up completeness. The average period of late TTE was $3.9 \pm 3.3$ years postoperatively (median, 3.4 years; interquartile range, $1.24-5.8$ years; maximum, 13.4 years).

AR was graded as either none or trivial (grade 0 ), mild (grade $1+$ ), moderate (grade 2+), moderate to severe (grade $3+$ ), severe (grade 4+) according to color flow mapping and continuous wave and pulsed wave Doppler by 2 expert echocardiographers (D.H.L. and A.-S.B.), who specifically focused on the vena contracta width and AR timing and mechanism.

\section{Statistical Analysis}

Continuous variables are expressed as the mean \pm 1 standard deviation or median and interquartile range. The Mann-Whitney rank sum test was used to compare the 2-group continuous variables. Categorical data were tabulated in $2 \times \mathrm{n}$ tables, and 2-group comparisons were made using the chi-square test or Fisher's exact probability test. The Kaplan-Meier method was used to calculate the nonadjusted actuarial survival and freedom from adverse events; a statistical comparison of event rates was determined using log-rank calculations. For perspective, age-, gender-, and race-matched survival estimates for the US population were calculated. To identify the 
TABLE 1. Baseline clinical patient characteristics

\begin{tabular}{|c|c|c|c|}
\hline Characteristic & $\begin{array}{c}\text { TAV } \\
(\mathbf{n}=\mathbf{1 7 0})\end{array}$ & $\begin{array}{c}\text { BAV } \\
(n=63)\end{array}$ & $\begin{array}{c}P \\
\text { value }\end{array}$ \\
\hline \multicolumn{4}{|l|}{ Age $(y)$} \\
\hline Mean \pm SD & $36 \pm 13$ & $43 \pm 12$ & $<.001$ \\
\hline Range & $11-68$ & $19-64$ & \\
\hline Male gender & $115(67)$ & $50(80)$ & .08 \\
\hline \multicolumn{4}{|l|}{ Height $(\mathrm{cm})$} \\
\hline Mean \pm SD & $184 \pm 12$ & $175 \pm 24$ & .003 \\
\hline Range & $148-214$ & $155-198$ & \\
\hline \multicolumn{4}{|l|}{ Weight (kg) } \\
\hline Mean \pm SD & $81 \pm 19$ & $84 \pm 19$ & .002 \\
\hline Range & $30-152$ & $42-127$ & \\
\hline \multicolumn{4}{|l|}{ BMI $\left(\mathrm{kg} / \mathrm{m}^{2}\right)$} \\
\hline Mean \pm SD & $24 \pm 5$ & $26 \pm 16$ & $<.001$ \\
\hline Range & $11-48$ & $13-45$ & \\
\hline \multicolumn{4}{|l|}{$\operatorname{BSA}\left(\mathrm{m}^{2}\right)$} \\
\hline Mean \pm SD & $2.0 \pm 0.3$ & $2.0 \pm 0.3$ & .798 \\
\hline Range & $1.1-2.7$ & $1.4-2.6$ & \\
\hline Hypertension & $44(26)$ & $23(37)$ & \\
\hline Diabetes (oral treatment or insulin) & $4(2)$ & $2(3)$ & \\
\hline Marfan syndrome & $91(54)$ & $3(5)$ & $<.001$ \\
\hline Loeys-Dietz syndrome & $8(5)$ & 0 & \\
\hline Acute aortic dissection & 0 & 0 & \\
\hline Sinus rhythm & $170(100)$ & $63(100)$ & \\
\hline \multicolumn{4}{|l|}{ LVEF (\%) } \\
\hline Median & 61 & 62 & .1 \\
\hline IQR & $57-65$ & $60-65$ & \\
\hline \multicolumn{4}{|l|}{ Aortic root diameter $(\mathrm{cm})$} \\
\hline Median & 5.0 & 4.3 & $<.001$ \\
\hline IQR & $4.6-5.4$ & $3.9-4.8$ & \\
\hline \multicolumn{4}{|l|}{ Aortic ascending diameter $(\mathrm{cm})$} \\
\hline Median & 3.8 & 4.9 & $<.001$ \\
\hline IQR & $3.0-4.8$ & $4.4-5.3$ & \\
\hline \multicolumn{4}{|l|}{ Aortic regurgitation } \\
\hline None/trivial & 66 & 23 & \\
\hline Mild & 43 & 21 & \\
\hline Moderate to severe & 43 & 9 & \\
\hline Severe & 18 & 10 & \\
\hline Average & $1.9 \pm 1.3$ & $1.7 \pm 1.5$ & \\
\hline Previous cardiovascular surgery & $8(5)$ & $4(6)$ & \\
\hline
\end{tabular}

Data presented as mean \pm standard deviation, median and IQR, or $\mathrm{n}(\%) . B A V$, Bicuspid aortic valve; $B M I$, body mass index; $B S A$, body surface area; $E F$, ejection fraction; $I Q R$, interquartile range; NYHA, New York Heart Association; TAV, tricuspid aortic valve.

predictors of outcome, we used univariate Cox regression proportional hazard models. Commercially available statistics and graphing packages, SigmaPlot and SigmaStat, version 11.0 (Systat Software, San Jose, Calif) were used for descriptive and analytical statistical procedures. A probability value of less than .05 was considered statistically significant. The Stanford institutional review board approved the present study, and informed consent was obtained from the patients at the time of contact.

\section{RESULTS}

Survival

The in-hospital (30-day) mortality rate was $0.9 \%$ $(2 / 233)$. One death was from complications arising from reimplantation of a small, nondominant right coronary artery with subsequent right ventricular failure. The second death was from cerebral infarction in a patient with a chronic aortic dissection. Early (30-day) morbidity is summarized in Table E1 and late complications in Table E2.

Two late deaths occurred. One patient committed suicide 6 weeks postoperatively and one patient with MFS died of cardiomyopathy 10 years postoperatively. The actuarial survival estimate at 5 and 10 years was $98.7 \% \pm 0.7 \%$ and $93.5 \% \pm 5.1 \%$, respectively (Figure $2, A$ ).

Survival after V-SARR was not significantly different than that of the general US population, matched for age, gender, and race (Figure 2,B). No significant difference was seen in mid-term survival after V-SARR between the TAV and BAV subsets $(P=.805)$; however, caution in interpreting this finding is necessary because the cumulative follow-up was much shorter in the BAV subset (TAV, 886 years; BAV, 216 years; Figure 2,C). Similarly, no statistically significant difference was seen in survival between those patients with a diagnosis of CTD and the rest of the population $(P=.793$, Figure $2, D)$.

\section{Reoperation}

A total of 6 patients required reoperation on the aortic root for any cause. The freedom from reoperation at 5 and 10 years was $98.0 \% \pm 1.2 \%$ and $92.2 \% \pm 3.6 \%$, respectively (Figure $3, A$ ). No demonstrable difference was seen in reoperation between the TAV and BAV subsets $(P=.179$; Figure $3, B)$ or between those with MFS or other CTDs and the rest of the patients $(P=.973$; Figure $3, C)$. One young patient with MFS required mitral valve replacement because of progressive mitral regurgitation 6 years after V-SARR; he requested replacement of his wellfunctioning native aortic valve at that time to avoid a potential third reoperation because he opted for a mechanical mitral valve.

\section{Endocarditis}

Two patients developed endocarditis; both had an uncomplicated early postoperative course. Neither had a positive blood culture at reoperation, but both had been treated with antibiotics previously for nonspecific symptoms. One infected BAV patient underwent AVR with a homograft 1 year postoperatively. The second patient with TAV had a localized infection near the right coronary artery reimplantation site; local resection and debridement were performed successfully.

\section{Late Aortic Dissection}

Six patients developed acute Stanford type B aortic dissection 19 to 103 months postoperatively, a serious problem. Five were female patients, and all had an underlying CTD (5 with MFS and 1 with Loeys-Dietz syndrome; Table E3). None had undergone concomitant arch replacement. All patients were treated conservatively and, to 

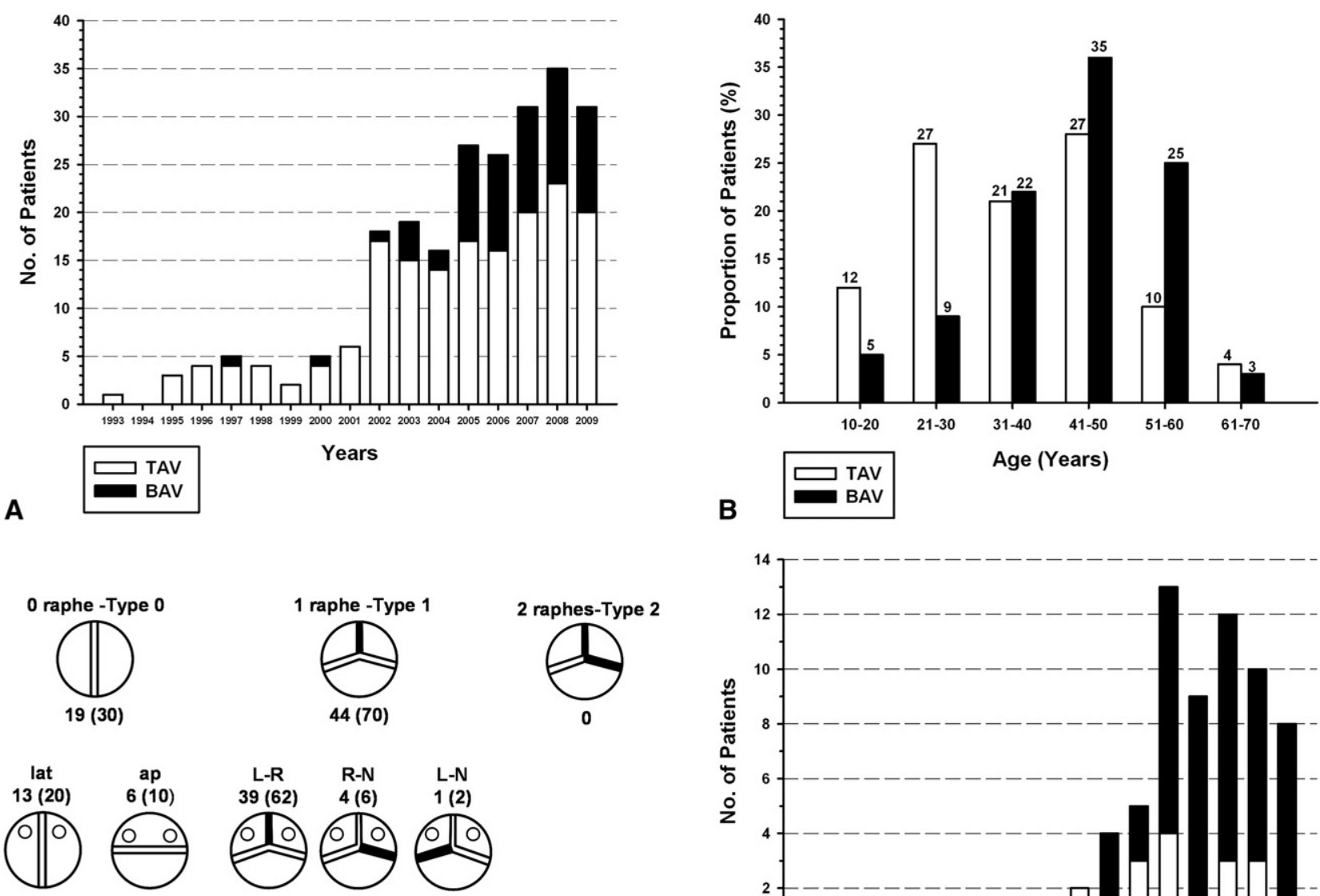

C

FIGURE 1. A, Distribution of patients undergoing valve-sparing aortic root replacement according to type of aortic valve. B, Age distribution of patients with tricuspid $(T A V)$ and bicuspid aortic valve $(B A V)$. C, Distribution of patients (n, \%) with a BAV according to Sievers' classification. D, Distribution of arch replacement during study period according to valve type.

date, subsequently have been doing well. The freedom from Stanford type B aortic dissection at 5 and 10 years was $97.5 \% \pm 1.2 \%$ and $90.4 \% \pm 5.0 \%$, respectively (Figure E1, A). A significant difference was seen in the freedom from acute Stanford type B dissection between those with MFS or other CTD and the rest of the patients $(P=.01$, Figure E1, $B)$.

\section{Aortic Valve Function}

At 5 and 10 years, the freedom from SVD was $97.6 \% \pm$ $1.4 \%$ and $96.1 \% \pm 2.1 \%$, respectively (Figure E2, $A$ ). No significant difference was found in SVD between the TAV and BAV subsets $(P=.639$; Figure E2, $B)$ nor between the patients with or without MFS or other CTDs $(P=.982$; Figure E2, $C)$. The characteristics of the 3 patients who required late AVR because of SVD are summarized in Table E4 (note, 1 patient with severe AR when the present study was closed [listed as SVD according to the guidelines] subsequently underwent AVR). The 4 patients who developed SVD during follow-up had either no or mild AR on the first postoperative echocardiogram. A significant difference was seen in the freedom from SVD and reoperation, however, between those patients with $4+$ AR preoperatively and the rest of the patients $(P<.001$, Figure E3, $A$ and $B$ ).

Based on the latest TTE, 202 patients $(94.8 \%)$ ) had either no or trace AR, $10(4.7 \%)$ had mild AR, 0 had moderate to severe AR, and $1(0.5 \%)$ had severe AR (who subsequently underwent AVR). Freedom from more than $2+\mathrm{AR}$ at 5 and 10 years was $97.4 \% \pm 1.5 \%$ and $95.3 \% \pm 2.5 \%$, respectively (Figure E1,C). Only 4 patients developed more than $2+$ AR during follow-up.

\section{Predictors of Adverse Events}

For the Cox regression analysis, we constructed a composite endpoint, but only 14 adverse events occurred 
TABLE 2. Intraoperative data for TAV and BAV patients undergoing Tirone David valve-sparing aortic root replacement

\begin{tabular}{|c|c|c|c|}
\hline Variable & $\begin{array}{c}\text { TAV } \\
(\mathbf{n}=\mathbf{1 7 0})\end{array}$ & $\begin{array}{c}\text { BAV } \\
(n=63)\end{array}$ & $\begin{array}{c}P \\
\text { value }\end{array}$ \\
\hline \multicolumn{4}{|l|}{ Urgency of surgery (n) } \\
\hline Elective & 168 & 63 & \\
\hline Urgent & 2 & 0 & \\
\hline Emergent & 0 & 0 & \\
\hline \multicolumn{4}{|l|}{$\begin{array}{c}\text { Perioperative annular } \\
\text { diameter }(\mathrm{cm})\end{array}$} \\
\hline Median & 28 & 27 & .238 \\
\hline IQR & $25-30$ & $25-30$ & \\
\hline \multicolumn{4}{|l|}{ CPB time (min) } \\
\hline Median & 265 & 309 & $<.001$ \\
\hline IQR & 239-301 & $275-330$ & \\
\hline \multicolumn{4}{|c|}{ Aortic crossclamp time (min) } \\
\hline Median & 211 & 242 & $<.001$ \\
\hline IQR & $184-241$ & $212-262$ & \\
\hline Arch repair & $17(10)$ & $48(76)$ & $<.001$ \\
\hline \multicolumn{4}{|l|}{ SACP time (min) } \\
\hline Median & 25 & 27 & .758 \\
\hline IQR & $22-34$ & $23-31$ & \\
\hline Axillary/innominate & $5 / 14$ & $1 / 46$ & \\
\hline Concomitant procedures & $39(23)$ & $6(10)$ & .02 \\
\hline Mitral valve repair & 13 & 2 & \\
\hline $\mathrm{PFO}$ & 29 & 2 & \\
\hline ASD & 6 & 1 & \\
\hline VSD & 1 & 0 & \\
\hline CABG & 4 & 2 & \\
\hline IABP & 4 & 3 & \\
\hline VAD & 3 & 1 & \\
\hline Aortic valve cusp repair & $63(37 \%)$ & $42(67)$ & $<.001$ \\
\hline Cusp FM shortening & 63 & 42 & \\
\hline Gore-Tex neochords & 0 & 3 & \\
\hline Triangular resection & 0 & 7 & \\
\hline
\end{tabular}

Data presented as n (\%) or median and IQR. ASD, Atrial septal defect; BAV, bicuspid aortic valve; $C A B G$, coronary artery bypass grafting; $C P B$, cardiopulmonary bypass; $F M$, free margin; $I A B P$, intra-aortic balloon pump; $I Q R$, interquartile range; $P F O$, patent foramen ovale; $S A C P$, selective antegrade cerebral perfusion; $T A V$, tricuspid aortic valve; $V A D$, ventricular assist device; $V S D$, ventricular septal defect.

(4 deaths [2 in-hospital and 2 late], 4 SVD, 3 reoperations [not due to SVD, 2 caused by endocarditis], 1 stroke, and 2 transient ischemic attack). This small number of events meant the Cox analysis model was unstable, which resulted in unreliable results without clinical relevance (Table E5). The extremely wide $95 \%$ confidence intervals for the variables with a significant hazard ratio (age, arch replacement, $\mathrm{AR}>2+$ preoperatively) are noteworthy.

\section{DISCUSSION}

In the present retrospective analysis, we observed that survival after elective Tirone David V-SARR in carefully selected, relatively young patients is excellent out to 10 years. So far, it is a safe and-most importantly-durable procedure, irrespective of valve type (TAV or BAV) or the presence of MFS or another CTD. The one technique used for root replacement is a strength compared with other reports. $^{17,18}$

\section{Different V-SARR Techniques and Modifications of Original Tirone David Procedure}

Of 450 patients undergoing Tirone David-I V-SARR, the long-term results for 126 patients $(20.6 \%$ MFS, only $4.0 \%$ $\mathrm{BAV}$, no information provided regarding aortic cusp repair) who underwent surgery from 1993 to 2000, were recently reported by Shrestha and colleagues ${ }^{19}$ from Hannover. The mean follow-up was $10 \pm 2$ years; 44 patients remained at risk at 10 years. The survival estimate was $93 \%, 85 \%$, and $70 \%$ at 1,5 , and 10 years, respectively. Although lower than the survival for our patients, any difference was probably due to differences in the patient substrate (eg, inclusion of patients with acute type A aortic dissection in the Hannover series). It is theoretically plausible, however, that this difference was due in part to more physiological postoperative aortic root physiology because we used the Tirone David-V-Stanford modification procedure. The freedom from AVR was $96 \%, 91 \%$, and $87 \%$ at 1,5 , and 10 years, respectively. ${ }^{19}$ MFS was a possible predictor of reoperation and overall mortality.

David and colleagues ${ }^{20}$ from Toronto reported the results for 167 patients (38\% MFS, 7\% BAV) who underwent V-SARR. The 10-year survival and freedom from moderate to severe AR estimate was $92 \% \pm 3 \%$ and $94 \% \pm 4 \%$, respectively. ${ }^{20}$ These survival and durability observations paralleled our findings.

The high rate of recurrent AR due to annular dilatation, eventually mandating reoperation, after only 5 years using the Yacoub remodeling V-SARR procedure ${ }^{21}$ has convinced most to abandon its use, especially in patients with MFS. The Yacoub remodeling procedure (or Tirone David-II or -III) was used in only 3 other adult patients at Stanford since 1993.

In 2010, De Paulis and colleagues ${ }^{22}$ reported the results in 278 patients $(15 \% \mathrm{MFS}, 11 \% \mathrm{BAV}$, aortic cusp repair in $9 \%$ ) from 4 Italian centers using a prefabricated Valsalva graft for David reimplantation V-SARR. Survival at 10 years and freedom from AR requiring reintervention was $91 \%$ and $88 \%$, respectively, ${ }^{22}$ inferior to the outcomes reported in the present analysis. This commercial Valsalva graft is popular; our Tirone David-V Stanford modification technique also creates large billowing neosinuses but is customized for each individual patient's pathologic anatomy.

The Hospital Universitaria 12 Octubre group in Madrid reported on 120 patients ( $43 \% \mathrm{MFS}, 12 \% \mathrm{BAV}, 76 \%$ receiving a Tirone David-V-Stanford modification V-SARR) and showed a 5-year survival and freedom from more than $2+$ AR estimate of $97 \%$ and $96 \%$, respectively. ${ }^{23}$ This corroborates our findings and demonstrates the reproducibility of the Tirone David-V-Stanford modification procedure at other experienced institutions. 

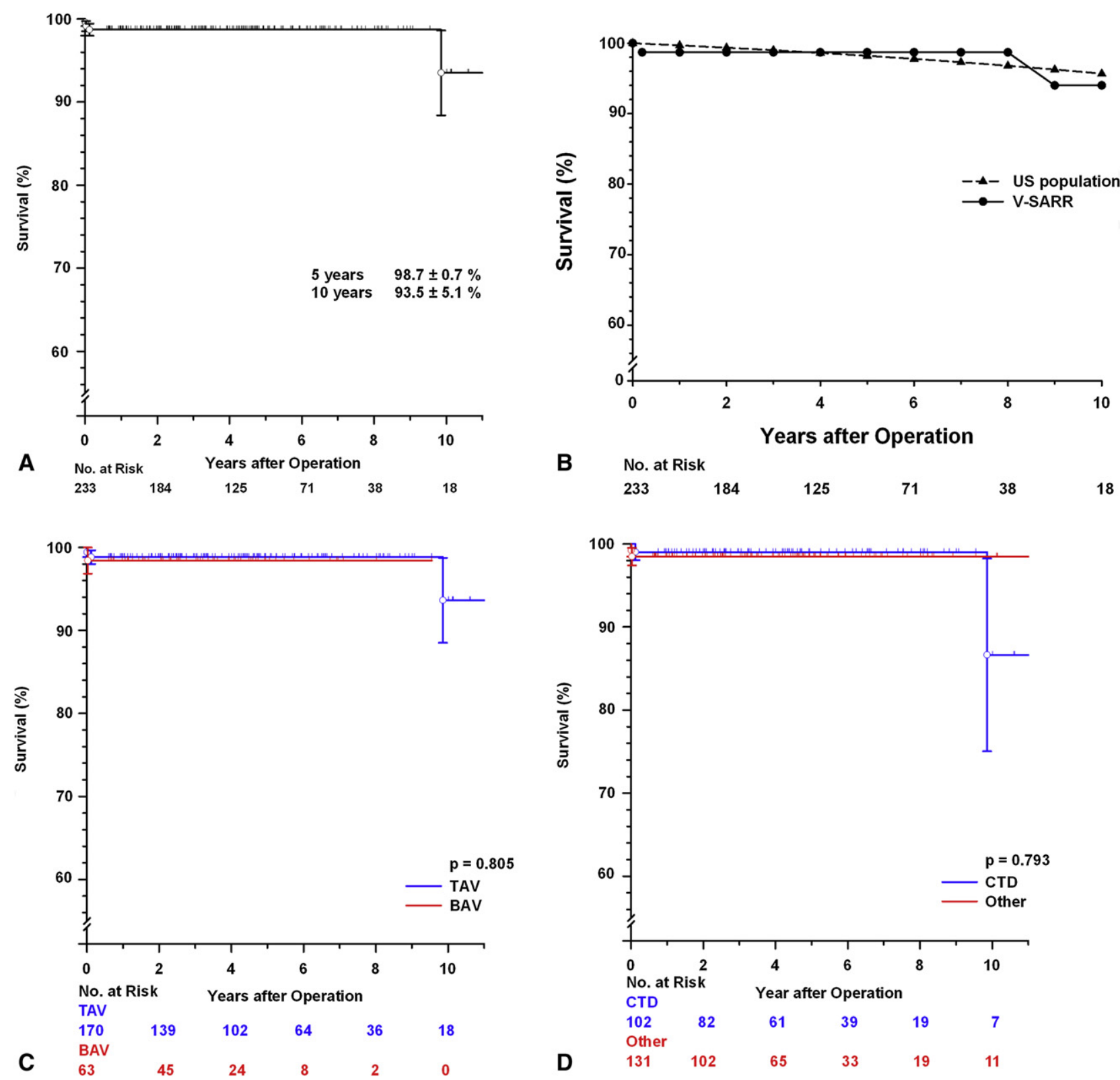

FIGURE 2. A, Kaplan-Meier survival curve for 233 patients undergoing valve-sparing aortic root replacement. B, Kaplan-Meier survival curve of 233 patients undergoing valve-sparing aortic root replacement compared with general US population matched for age, gender, and race. C, Kaplan-Meier survival curves comparing tricuspid $(T A V)$ and bicuspid aortic valve $(B A V)$ subsets. D, Kaplan-Meier survival curves comparing patients with confirmed diagnosis of Marfan syndrome or other connective tissue disorders (CTDs) compared with remainder of patients. Vertical bars represent \pm 1 standard error.

\section{V-SARR for Patients With BAV}

Although patients with BAV had significantly longer cardiopulmonary bypass and aortic crossclamp times and more commonly required concomitant aortic arch replacement or cusp-free margin repair (Table 2) compared with the TAV cohort, the clinical outcome in this subset was not different from that of the TAV subcohort to date. This underlines that the Tirone David procedure, with proper patient selection, is an excellent option for patients with regurgitant BAVs; however, longer follow-up is necessary. These results are consistent with those from other investigators ${ }^{24}$; however, the largest experience with V-SARR for BAV used aortic root remodeling (Yacoub), isolated BAV repair without root replacement, or ascending aortic replacement alone, but not V-SARR using the reimplantation technique. ${ }^{25}$ Because substantial annular dilatation is a hallmark of BAV and causes AR owing to inadequate cusp coaptation height, the use of a V-SARR procedure that does not reduce the aortic annular size is not prudent. Despite equal durability to date in our experience, 

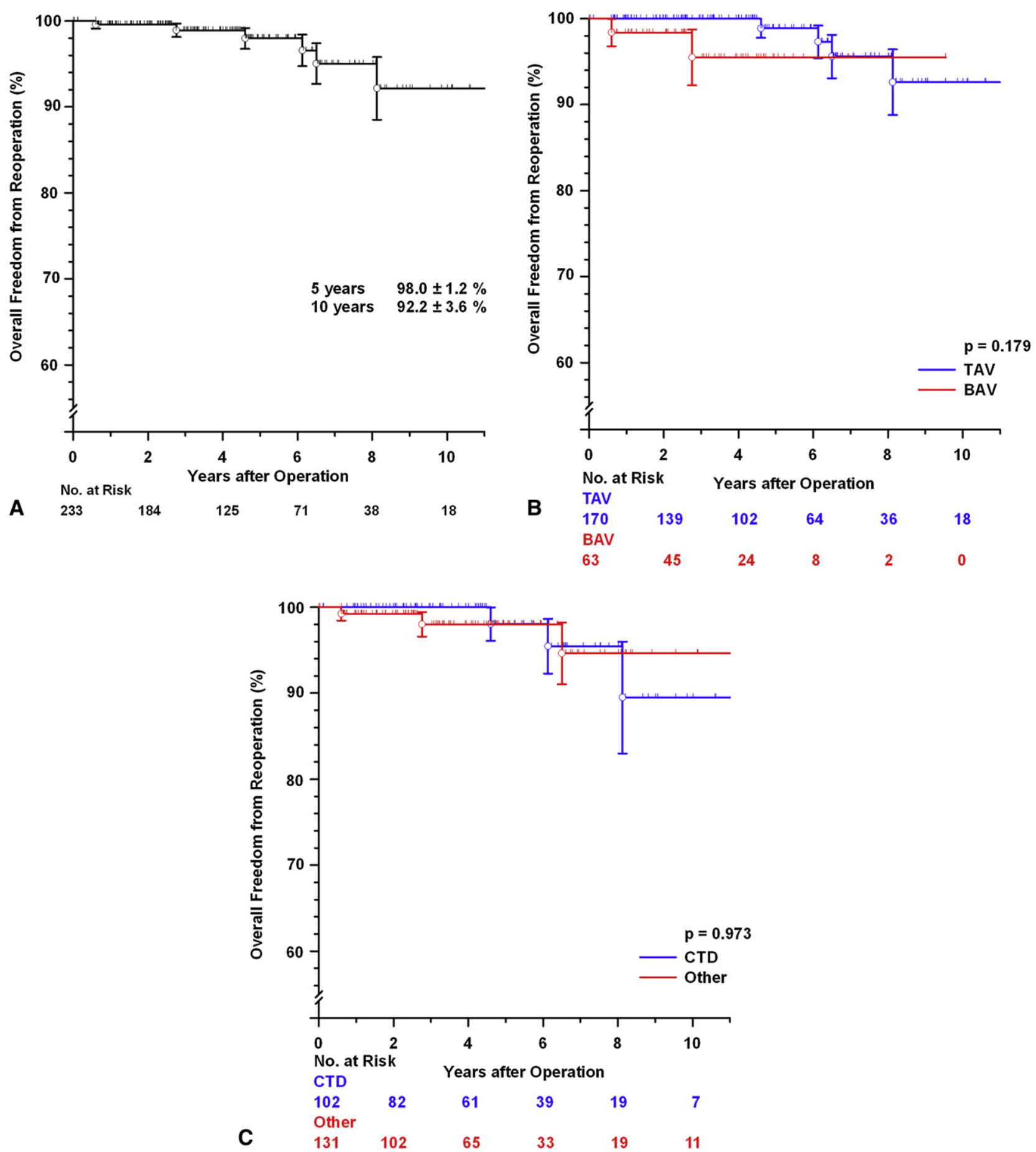

FIGURE 3. A, Freedom from reoperation on aortic root after valve-sparing aortic root replacement. B, Freedom from reoperation on aortic root comparing tricuspid $(T A V)$ and bicuspid aortic valve $(B A V)$ subsets. C, Freedom from reoperation on aortic root after valve-sparing aortic root replacement comparing patients with confirmed Marfan syndrome or another connective tissue disorder $(C T D)$ and remainder of patient cohort. Vertical bars represent \pm 1 standard error.

we believe the V-SARR long-term durability in patients with a BAV will eventually prove to be inferior than that for patients with a TAV because the bicuspid valves inexorably and progressively become more fibrotic and eventually stenotic. ${ }^{8}$ This makes careful patient selection crucial. We avoid V-SARR in older patients with a BAV and those with moderately severe fibrosis or calcification of the valve. 
We, and Fazel and colleagues, ${ }^{15}$ showed that a large number of BAV patients $(>70 \%)$ have aortic arch dilatation (ie, Stanford-Fazel clusters III and IV BAV-associated aortopathy). This is reflected in our V-SARR experience, in which arch replacement was performed in $76 \%$ of the BAV patients compared with only $10 \%$ of the TAV patients. BAV aortopathy and arch dilatation is addressed more aggressively at Stanford in these young patients (average age, 43 \pm 12 years) undergoing elective procedures than recommended by others. ${ }^{26}$ Although the natural history of BAV indicates a relative low risk of reintervention on the arch in patients after isolated aortic valve replacement, ${ }^{27}$ most of these Ontario patients were older. The Mayo Clinic group has recommended not replacing the transverse aortic arch in patients with BAV disease, ${ }^{26}$ but average age was $55.8 \pm$ 14.9 years, the arch diameter was only $3.4 \pm 0.6 \mathrm{~cm}$, $50 \%$ had aortic stenosis, $7 \%$ had mixed aortic stenosis/ $\mathrm{AR}$, and $89 \%$ underwent AVR. In such a patient population, we also would not replace the arch. These are different phenotypes of BAV disease. Although we do not proclaim "nearly routine" replacement of the aortic arch in patients with BAV, being aware that in most institutions, arch procedures under hypothermic circulatory arrest carries substantial additional morbidity and mortality, it is performed often at Stanford, without any added risk of death or stroke.

The present series included $63 \mathrm{BAV}$ patients (or $27 \%$ ). In contrast, only $4 \%$ of the Hannover Tirone David-I series had a $\mathrm{BAV}^{19}$; thus, comparing outcomes with respect to valve morphology is difficult. Our cohort contained a fairly large fraction of patients with El Khoury type II AR (ie, cusp prolapse). Most BAV patients with AR due to cusp prolapse had an eccentric AR jet visualized on the preoperative echocardiogram. Hanke and colleagues ${ }^{6}$ advocated avoiding V-SARR in such patients because of a greater likelihood of AR recurrence. Our BAV patients with type II AR have had excellent clinical and echocardiographic results so far; however, those with $4+$ AR preoperatively did not do as well (Figure E3, $A$ and $B$ ). The fairly high number of cusp repair procedures (TAV 37\%, BAV 67\%) had no demonstrable adverse effect on the outcomes in our analysis, in contrast to what Hanke and colleagues ${ }^{6}$ observed. However, we simply shortened the cusp-free margin without resorting to complete cusp plication, which reduces the available cusp area.

Regarding the distribution of BAV types encountered compared with the original seminal publication by Sievers and colleagues, ${ }^{12}$ the 304 patients reported by Sievers and colleagues had undergone either valve replacement or preservation and were subdivided as type 0 ("naturally perfect BAV") in $7 \%$, type 1 ( 1 raphé) in $88 \%$, and type 2 (2 raphés) in $5 \%$. In our V-SARR series, the distribution was type 0 in $30 \%$, type 1 in $70 \%$, and type 2 in none. This dramatic difference is explained by the far fewer V-SARR procedures in the experience reported by Sievers and colleagues, ${ }^{12}$ in which reimplantation or remodeling V-SARR was used in only $1.6 \%$ and $1 \%$ of patients, respectively.

\section{V-SARR in Setting of CTD}

Patel and colleagues ${ }^{28}$ reported good early results after V-SARR in 31 patients with Loeys-Dietz syndrome. We only had 8 patients with Loeys-Dietz syndrome, and all did well, except for 1 patient, who later sustained an acute type B dissection. Because many patients with CTD are actively lobbying for a V-SARR procedure, a randomization trial between V-SARR and CVG would be unrealistic. The safety and long-term durability of the CVG procedure in patients with MFS has been well documented. In the worldwide series of 675 patients with MFS compiled by Gott and colleagues ${ }^{9}$ in 1999, survival was $94 \%, 91 \%$, and $59 \%$ at 5,10 , and 20 years, respectively (159 and 4 patients at risk at 10 and 20 years, respectively). Most MFS patients are young and therefore usually receive a mechanical valve as a part of the CVG $(89 \%$ in the report by Gott and colleagues ${ }^{9}$ ) owing to the limited durability of bioprosthetic and homograft valves. Among the patients who received a CVG and were discharged alive from hospital, $90 \%$ were free of a thromboembolic event at 20 years. ${ }^{9}$ Three patients in our Tirone David V-SARR series sustained a thromboembolic event ( 2 transient ischemic attacks and 1 stroke), and none had a hemorrhagic complication.

In 2009, David and colleagues ${ }^{7}$ reported on 103 patients with MFS who underwent either a Yacoub procedure or Tirone David reimplantation V-SARR during 18 years. The overall results were satisfactory but were inferior for those who had undergone a Yacoub remodeling procedure. It is important to emphasize that only 29 V-SARR patients remained at risk at 10 years; therefore, we still do not know with certainty how durable V-SARR for patients with MFS will be 10 to 20 years later.

All 6 patients in our series who sustained a new type B aortic dissection had a CTD (5 MFS; Table E3 and Figure E1, A and $B$ ). Most had been, or were currently, taking losartan, another angiotensin II receptor blocker or an angiotensinconverting enzyme inhibitor. Although anecdotal, this has prompted us to avoid angiotensin II receptor blocker or angiotensin-converting enzyme inhibitor therapy postoperatively in patients with a CTD. David and colleagues ${ }^{7}$ also noted that most late deaths were related to downstream aortic dissection-related complications. Furthermore, computational fluid dynamic studies have suggested that an ascending aortic graft increases the distal pulse pressure and might exacerbate systolic hypertension. ${ }^{29}$

A Tirone David V-SARR procedure is an excellent option for most patients with aortic root aneurysm if the aortic valve cusps are structurally normal, even if AR is present because of sinotubular junction or annular dilatation or cusp prolapse, because the AR can be corrected by restoring 
normal annular and sinotubular junction geometry (with or without cusp reconstruction). Yacoub remodeling should be avoided if annular dilatation is present. Structurally abnormal valve cusps, including severe fibrosis, calcification, or multiple perforations, are contraindications to V-SARR. The 20-year prognosis of patients undergoing V-SARR compared with CVG remains unknown, especially in terms of all valve-related morbidity and mortality. Therefore, patients who desire V-SARR to avoid anticoagulation must accept an unknown-but finite-risk of reoperation in their lifetimes as a trade-off.

\section{Study Limitations}

The present investigation was a retrospective analysis, albeit the data were collected prospectively. Only 18 patients remained at risk beyond 10 years ( 7 with MFS); thus, only cautious statements about late results can be supported. Only 14 adverse events occurred, precluding the use of a hazard model to identify patient- or disease-related variables or technical factors associated with a greater likelihood of complications. This highlights the need for rigorous inspection of larger numbers of patients for longer follow-up periods before we can conclusively learn the actual long-term durability of Tirone David V-SARR. Clinically important adverse events (eg, stroke, hemorrhagic events, infection, SVD, reoperation) occurred rarely, which would make randomized, prospective studies prohibitively expensive and unrealistic. The present report included only selected patients undergoing elective, first-time V-SARR; more studies similar to that by Leshnower and colleagues $^{30}$ from Emory are needed to comprehensively assess the results of V-SARR in acute settings, especially for patients with acute type A aortic dissection. However, the Hannover group is urging caution about performing VSARR in patients with acute dissection because of the greater mortality. ${ }^{19}$

AR generally is well tolerated; therefore, it is essential to report the severity of echocardiographic residual/recurrent AR over time in all surviving patients and not just rely on the need for reoperation. Because different groups have used different AR grading systems, and some have reported only severe AR postoperatively, meaningful comparisons between reports are difficult. One surgeon (D.C.M.) operated on nearly all these Stanford patients, making generalization of the results to other surgeons or institutions speculative. Finally, patient-referral and patient-selection biases were likely present.

\section{CONCLUSIONS}

Tirone David reimplantation V-SARR was associated with excellent clinical and functional outcomes out to 5 to 10 years in patients with and without associated CTDs (primarily MFS) or with a BAV. The incidence of more than $2+$ $\mathrm{AR}$ or reoperation at 10 years was very low. Additional follow-up is required, however, to characterize the risks, hazards, and outcomes of V-SARR beyond 10 years.

We thank Stanford Professor Mark Hlatky, MD, for providing comparative US survival data. We also appreciate and acknowledge the efforts of Michael Sheehan, MSN, RNFA, NPc, in following up patients and capturing late echocardiograms.

\section{References}

1. Miller DC. Valve-sparing aortic root replacement: current state of the art and where are we headed? Ann Thorac Surg. 2007;83:S736-9; discussion, S785-90.

2. Sarsam MA, Yacoub M. Remodeling of the aortic valve annulus. J Thorac Cardiovasc Surg. 1993;105:435-8.

3. David TE, Feindel CM. An aortic valve-sparing operation for patients with aortic incompetence and aneurysm of the ascending aorta. J Thorac Cardiovasc Surg. 1992;103:617-22.

4. Kallenbach K, Karck M, Pak D, Salcher R, Khaladj N, Leyh R, et al. Decade of aortic valve sparing reimplantation: are we pushing the limits too far? Circula tion. 2005;112:I253-9.

5. Zehr KJ, Thubrikar MJ, Gong GG, Headrick JR, Robicsek F. Clinical introduction of a novel prosthesis for valve-preserving aortic root reconstruction for annuloaortic ectasia. J Thorac Cardiovasc Surg. 2000;120:692-8.

6. Hanke T, Charitos EI, Stierle U, Robinson D, Gorski A, Sievers HH, et al. Factors associated with the development of aortic valve regurgitation over time after two different techniques of valve-sparing aortic root surgery. J Thorac Cardiovasc Surg. 2009;137:314-9.

7. David TE, Armstrong S, Maganti M, Colman J, Bradley TJ. Long-term results of aortic valve-sparing operations in patients with Marfan syndrome. J Thorac Cardiovasc Surg. 2009; 138:859-64.

8. Svensson LG, Batizy LH, Blackstone EH, Gillinov AM, Moon MC, D'Agostino RS, et al. Results of matching valve and root repair to aortic valve and root pathology. J Thorac Cardiovasc Surg. 2011;142:1491-8.e7.

9. Gott VL, Greene PS, Alejo DE, Cameron DE, Naftel DC, Miller DC, et al. Replacement of the aortic root in patients with Marfan's syndrome. N Engl J Med. 1999;340:1307-13.

10. Gott VL, Cameron DE, Alejo DE, Greene PS, Shake JG, Caparrelli DJ, et al. Aortic root replacement in 271 Marfan patients: a 24-year experience. Ann Thorac Surg. 2002;73:438-43.

11. Tang GH, Maganti M, David TE, Feindel CM, Scully HE, Borger MA. Effect of prior valve type on mortality in reoperative valve surgery. Ann Thorac Surg. 2007;83:938-45.

12. Sievers HH, Schmidtke C. A classification system for the bicuspid aortic valve from 304 surgical specimens. J Thorac Cardiovasc Surg. 2007;133:1226-33.

13. Demers P, Miller DC. Simple modification of "T. David-V" valve-sparing aortic root replacement to create graft pseudosinuses. Ann Thorac Surg. 2004;78:1479-81.

14. Itoh A, Fischbein M, Arata K, Miller DC. "Peninsula-style" transverse aortic arch replacement in patients with bicuspid aortic valve. Ann Thorac Surg. 2010;90:1369-71.

15. Fazel SS, Mallidi HR, Lee RS, Sheehan MP, Liang D, Fleischman D, et al. The aortopathy of bicuspid aortic valve disease has distinctive patterns and usually involves the transverse aortic arch. J Thorac Cardiovasc Surg. 2008;135 901-7.e2.

16. Akins CW, Miller DC, Turina MI, Kouchoukos NT, Blackstone EH, Grunkemeier GL, et al. Guidelines for reporting mortality and morbidity after cardiac valve interventions. J Thorac Cardiovasc Surg. 2008;135:732-8.

17. de Kerchove L, Boodhwani M, Glineur D, Poncelet A, Verhelst R, Astarci P, et al Effects of preoperative aortic insufficiency on outcome after aortic valve-sparing surgery. Circulation. 2009;120:S120-6.

18. Aicher D, Fries R, Rodionycheva S, Schmidt K, Langer F, Schafers HJ. Aortic valve repair leads to a low incidence of valve-related complications. Eur J Cardiothorac Surg. 2009;37:127-32.

19. Shrestha M, Baraki H, Maeding I, Fitzner S, Sarikouch S, Khaladj N, et al. Longterm results after aortic valve-sparing operation (David I). Eur J Cardiothorac Surg. 2012;41:56-62.

20. David TE, Feindel CM, Webb GD, Colman JM, Armstrong S, Maganti M. Aortic valve preservation in patients with aortic root aneurysm: results of the reimplantation technique. Ann Thorac Surg. 2007;83:S732-5; discussion, S785-90.

21. Birks EJ, Webb C, Child A, Radley-Smith R, Yacoub MH. Early and long-term results of a valve-sparing operation for Marfan syndrome. Circulation. 1999;100: II29-35. 
22. De Paulis R, Scaffa R, Nardella S, Maselli D, Weltert L, Bertoldo F, et al. Use of the Valsalva graft and long-term follow-up. J Thorac Cardiovasc Surg. 2010;140: S23-7; discussion, S45-51.

23. Forteza A, Centeno J, Bellot R, Lopez Gude MJ, Perez de la Sota E, Sanchez V, et al. [Aortic valve sparing in 120 patients with aortic root aneurysms]. Rev Esp Cardiol. 2011;64:470-5.

24. Boodhwani M, de Kerchove L, Watremez C, Glineur D, Vanoverschelde JL, Noirhomme P, et al. Assessment and repair of aortic valve cusp prolapse: implications for valve-sparing procedures. J Thorac Cardiovasc Surg. 2011;141:917-25.

25. Schafers HJ, Kunihara T, Fries P, Brittner B, Aicher D. Valve-preserving root replacement in bicuspid aortic valves. J Thorac Cardiovasc Surg. 2010;140: S36-40; discussion, S45-51.

26. Park CB, Greason KL, Suri RM, Michelena HI, Schaff HV, Sundt TM III. Should the proximal arch be routinely replaced in patients with bicuspid aortic valve disease and ascending aortic aneurysm? J Thorac Cardiovasc Surg. 2011;142:602-7.

27. Tzemos N, Therrien J, Yip J, Thanassoulis G, Tremblay S, Jamorski MT, et al. Outcomes in adults with bicuspid aortic valves. JAMA. 2008;300:1317-25.

28. Patel ND, Arnaoutakis GJ, George TJ, Allen JG, Alejo DE, Dietz HC, et al. Valve-sparing aortic root replacement in Loeys-Dietz syndrome. Ann Thorac Surg. 2011;92:556-61.

29. Vardoulis O, Coppens E, Martin B, Reymond P, Tozzi P, Stergiopulos N. Impact of aortic grafts on arterial pressure: a computational fluid dynamics study. Eur J Vasc Endovasc Surg. 2011;42:704-10.

30. Leshnower BG, Guyton RA, Myung RJ, Puskas JD, Kilgo PD, McPherson L, et al. Expanding the indications for the David V aortic root replacement: early results. J Thorac Cardiovasc Surg. 2012;143:879-84.

\section{Discussion}

Dr Allan S. Stewart (New York, $N Y$ ). Thanks for the privilege of discussing this study. It really is a fantastic study with great early results. Your team should be proud of having an under $1 \%$ operative mortality for a complex operation.

It is a timely question, because right or wrong, we are changing the paradigm for how we are dealing with aortic valve disease. Surgeons are now implanting biological valves in younger and younger people, believing the propaganda from our device companies that the new valves are going to last 20,25 years, and by that point in time we will have worked out the valve-in-valve issue. So in that 30 -year-old patient, we are suggesting that there might be just 1 biological replacement followed by 1 or 2 valve-in-valves. Essentially, we are currently treating patients to prepare for a technology that is so far unapproved.

So, with that in mind, I have a few questions. The first of which is age. Your average age was low, around 40 years old, but you do have 1 or 2 patients who were older than 60 . You are advocating for valve-sparing operations with few data to support a 20 -year follow-up.

What do you tell your patients as far as the perceived longevity of a trileaflet or a bicuspid valve?

Dr Kvitting. Thank you very much, Dr Stewart, for your very insightful comments and questions. I should be careful to make comments on behalf of Dr Miller in this forum. But, in general, if the valve is repairable, it should be saved. If there are intraoperative findings that the valve and cusps are not suitable for repair, the valve should be excised, and the patient should receive a prosthetic valve. In older patients with a bicuspid aortic valve, because they will eventually become stenotic sooner than in young patients, there are other options that could be better than valve-sparing aortic root replacement; for example, a composite valve graft with a bioprosthesis or a Freestyle root replacement, which probably would give the patients a more durable result.
Dr Stewart. The second question I had is on bicuspid valves. It is a struggle now when we think about bicuspid valves in the setting of perhaps transcatheter valve rescue, because at the end of the day, it is still a bicuspid valve. It still has the same altered geometry of the annulus after a valve-sparing procedure; we are still plicating that conjoined leaflet and creating a more pronounced raphé. So when that valve fails in the future, might we be doing a disservice to our patients, because in its current iteration, our transcatheter solutions do not provide us a rescue for bicuspid valves, whether it is a native bicuspid or a valve-sparing bicuspid repair.

Dr Kvitting. That is a very good comment. If the transcatheter aortic valve replacement method holds its promise, it might be that these patients are better off if they receive a composite graft with, for example, a $3 \mathrm{~F}$ equine valve or another bioprosthesis that later will be more suitable for a valve-in-valve transcatheter aortic valve replacement procedure. But I still think that it is uncertain whether that leap of judgment will hold.

Dr Stewart. The next question is, when looking at your data, you had 3 early failures, all of which had severe preoperative aortic insufficiency (AI). You only treated 28 patients who started off with severe AI, so that is a little greater than a $10 \%$ early failure rate in those with severe AI. The 2 questions I have on that are, 1 , in the practice of your group, have you altered how you repair severe AI or perhaps abandoned doing severe AI? The third part of it is, philosophically, in those young patients who have 4.7-, $4.8-\mathrm{cm}$ aortas, 2 to $3+\mathrm{AI}$, you know they are going to require an operation at some point. Should we be advocating an earlier fix? I bring this up because when you have severe AI for a while, you are creating a lot of pressure down on the free edge of those cusps and destroying it, and perhaps that is a risk factor for early failure in a valve-sparing operation.

Dr Kvitting. Another good point. Three patients had severe aortic regurgitation at the initial surgery and sustained structural valve deterioration; 1 was a bicuspid valve with ruptured commissural suspensory chords that was fixed by resuspending the cusp with Gore-Tex suture neochords, which also was done in 2 other patients. Since that early failure, Dr Miller has abandoned this approach to correct ruptured suspensory chords with Gore-Tex sutures. The 2 other patients were both very young and had Marfan syndrome; both developed dilatation of their left ventricular outflow tract as the mechanism responsible for their recurrent aortic regurgitation. One of them, an 11-year-old patient, underwent valve-sparing aortic root replacement and complicated triple orifice mitral valve repair with 2 Alfieri stitches that perhaps, in hindsight, should not have been repaired.

Dr Stewart. The last comment is on your 2 most frequent complications. One was the need in 8 patients for a right coronary artery interposition graft, which seems fairly high. The reason cited was technical complications. However, that was 8 of 230. It seems like a lot of right coronary injuries requiring a graft. I was wondering what you do to correct that.

Also, then, your patients with Marfan syndrome; 6 with a type B dissection. I know that your group uses a pretty aggressive peninsula repair technique for the arch. I was unable to ferret out in your Marfan group if they had received that technique and perhaps that was predisposing them to a flow change in the distal arch and perhaps that was not predisposing them to a dissection. Do you have any comments on that? 
Dr Kvitting. I will start with your last question. None of these patients had undergone arch repair because they did not have bicuspid valves. We know from others, for example, Professor David's data from Toronto, that downstream complications, including the development of type B dissections, is known to occur in patients with Marfan syndrome, which mandates assiduous surveillance and careful $\beta$-blocker therapy with or without losartan. We do not believe these dissections were related directly or indirectly to our initial valve-preserving root replacement. Finally, regarding whether there was a high number of right coronary artery injuries requiring an interposition graft, I cannot personally comment on that. Sorry, sir.

Dr Smith. Dr Miller, did you want to answer that?

Dr D. Craig Miller (Stanford, Calif). Thank you, Craig. Being responsible for most of them, indeed, I can comment. Most of these patients had bicuspid valves and nondominant, small right coronary arteries that fell apart during reimplantation with a Carrel patch. As Tirone David and Nick Kouchoukos have shown, many early deaths after a Ross procedure result from trouble with a small, nondominant right coronary artery. Our solution for decades has been to do a very short $(2-3 \mathrm{~cm})$ interposition graft using the large saphenous vein harvested from the thigh, termed a "Kay-Zubiate". Jerome Kay and Pablo Zubiate in the late 1970s described how one can bail out of trouble with this little vein graft. Interestingly, I just saw this very old technique repopularized in a recent report with no reference whatsoever to the original publication from decades ago. But, it was due to technical problems, Allan; whether our rate was too high, I do not know, but I do take responsibility for these problems.

Dr Christian Etz (Leipzig, Germany). On the same topic on the bicuspids, you did not observe any difference in overall survival among the 3 groups, obviously reflecting not only excellent patient selection. We just presented our experience from Leipzig of a cohort of 476 patients of more than 1200 patients who underwent root replacement, all with the same mechanical composite prosthesis, at the Aortic Symposium in New York last week, and we found similar results as you just presented, with an overall longevity equivalent to an age- and gender-matched population after the first postoperative year.

A subgroup analysis, however, in our bicuspid patients revealed a significantly better long-term outcome; they were basically cured, but those with tricuspid valves had significantly worse longevity after discharge, clearly inferior to that of their age- and gender-matched normal population.

We also found, surprisingly, significantly worse longevity in women, a finding that we had previously seen among patients receiving biological conduits in our Sinai series. So I was wondering whether you had analyzed gender differences and could you comment on your understanding as to what might protect bicuspid patients down the road?

Dr Kvitting. We have to go back and study whether gender influenced the outcomes in our cohort. I saw your presentation in New York. I am wondering a little bit whether perhaps your data were biased because many of the tricuspid valves were probably associated with having some sort of connective tissue disorder in a greater proportion than in patients with a bicuspid aortic valve and that might be why having a bicuspid valve was protective, because they have less extensive aortic disease than the tricuspid population. But that is just guessing from my side.
Dr Etz. They were actually excluded. But perhaps it was because it is a mark of atherosclerosis. That was our understanding. Also, our tricuspid valve population was significantly older than yours, even older than those with bicuspid valves. So that also might have shifted this a little bit.

Dr Oz Shapira (Jerusalem, Israel). Thank you for an excellent presentation. My question is regarding the basic comparison groups. Given that you had a large proportion of patients with Marfan syndrome in the tricuspid aortic valve group and a separate bicuspid valve group, and given the large body of evidence suggesting that a bicuspid aortic valve is associated with connective tissue disease of the aorta itself, would it have been more logical to include the patients with Marfan syndrome and bicuspid aortic valve in 1 group and compare them with the patients with tricuspid aortic valves without Marfan syndrome? The long-term adverse outcomes in the present study were mostly affected by the presence of connective tissue disorder. Restructuring the study groups might make a large difference in interpreting the results.

Thank you.

Dr Kvitting. That is a very good and valid point. We just discussed that point a few days ago, that perhaps we are giving the patients with tricuspid valves more than just 1 disease because they are associated with a greater number of concomitant connective tissue disorders. But it might be valuable to just try to do that and group the valves together to determine whether valves with or without associated aortic disease have a different outcome.

Dr Tirone E. David (Toronto, Ontario, Canada). This is more a comment than a question. I think it is wonderful that you are doing this operation and trying to determine its limitations. Whoever read my very first paper or heard me presenting during the first decade, the sentence I used was "normal" aortic cusps. During the first decade of our experience, we never tried to do valve-sparing reimplantation or remodeling in patients who had abnormal cusps. As experience increased, we decided to treat patients with a bicuspid aortic valve and prolapsing or defective cusps with large fenestrations.

Last week in New York City I presented Dr Feindel's and my experience with 296 reimplantations only. The longest follow-up was 22 years. Unfortunately, only 21 patients were at risk at 15 years. Approximately one third had Marfan syndrome. Only 32 had bicuspid aortic valves. Only 11 patients developed moderate or severe aortic insufficiency, one third of them in bicuspid aortic valve group and none in the Marfan syndrome. Actually, on multivariate analysis, Marfan syndrome was the only independent predictor of AI on the beneficial side, that is, the hazard ratio was less than 1. In other words, in our hands, Marfan syndrome was protective, not detrimental, to good outcomes.

Bicuspid aortic valve on univariate analysis was predictor of failure but not on multivariate analysis. Again, our sample size was too small.

The anatomy of the bicuspid valve is highly variable. Type 0 is perfect for valve sparing. If you have type 1 or 2 and the further away the cusps are, the more difficult to perform a reimplantation into a cylinder or a Valsalva graft or the way you do the reimplantation.

I think we should be a bit more cautious with the reimplantation technique in bicuspid aortic valve. Actually, in any reimplantation, the cusps must be relatively normal for us to embark on this difficult operation.

Thank you. 

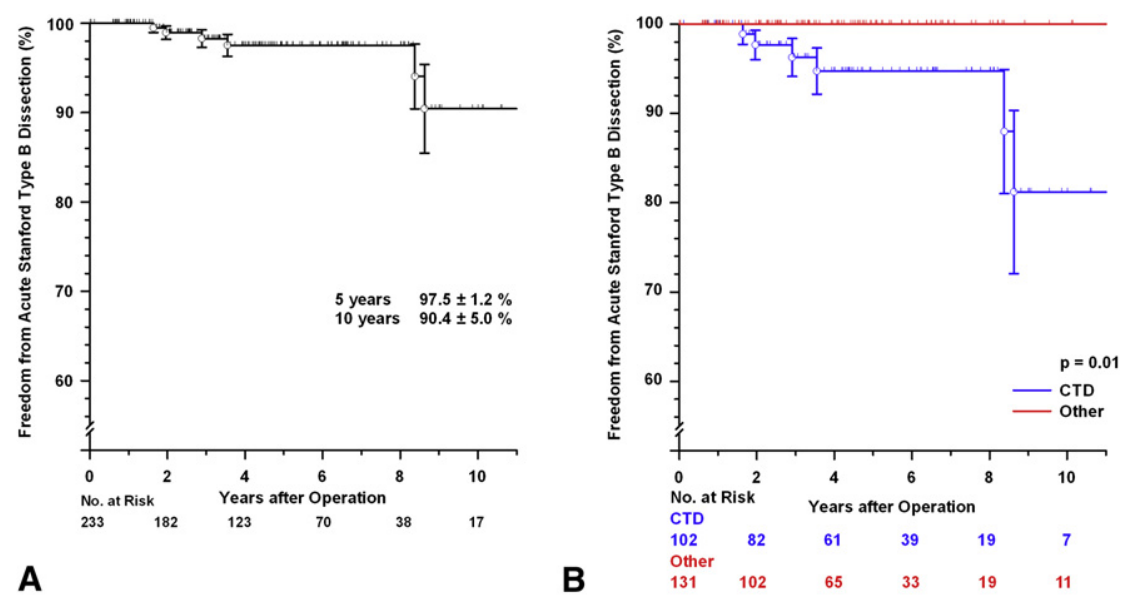

A

B

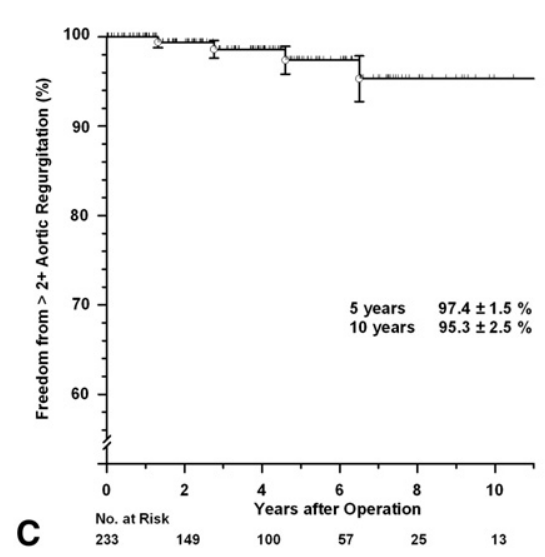

FIGURE E1. A, Freedom from Stanford type B aortic dissection for all patients. B, Freedom from Stanford type B aortic dissection comparing patients with confirmed diagnosis of Marfan syndrome or other connective tissue disorder (CTD) with remainder of patients. C, Freedom from more than $2+$ aortic regurgitation. Vertical bars represent \pm 1 standard error. 

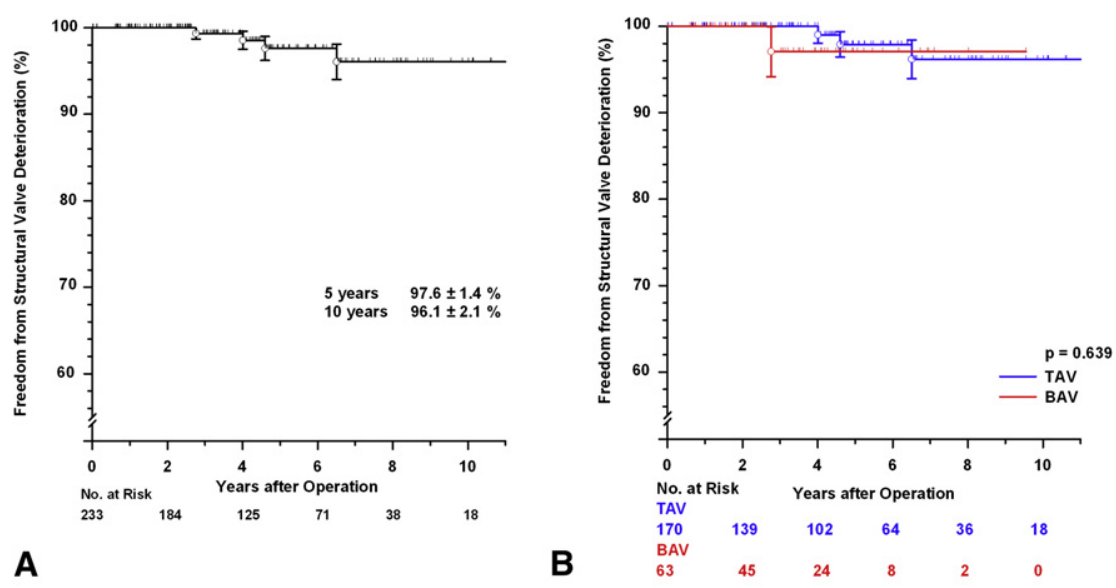

A

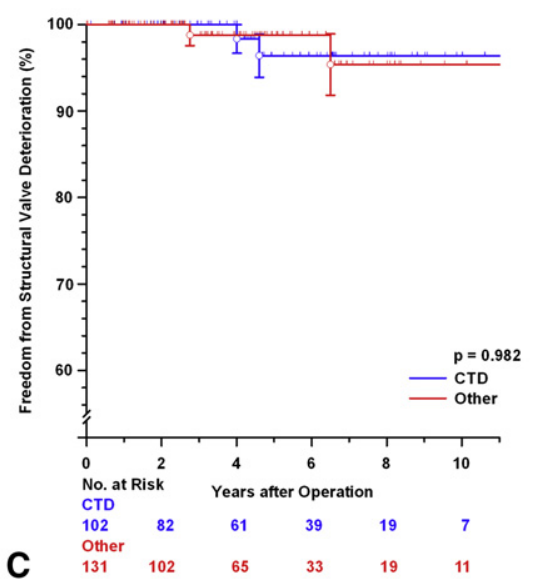

FIGURE E2. A, Freedom from structural valve deterioration ( $S V D)$ after valve-sparing aortic root replacement. B, Freedom from SVD comparing tricuspid $(T A V)$ and bicuspid aortic valve $(B A V)$ subsets. C, Freedom from SVD comparing patients with confirmed diagnosis of Marfan syndrome or other connective tissue disorder $(C T D)$ and remainder of patients. Vertical bars represent \pm 1 standard error 

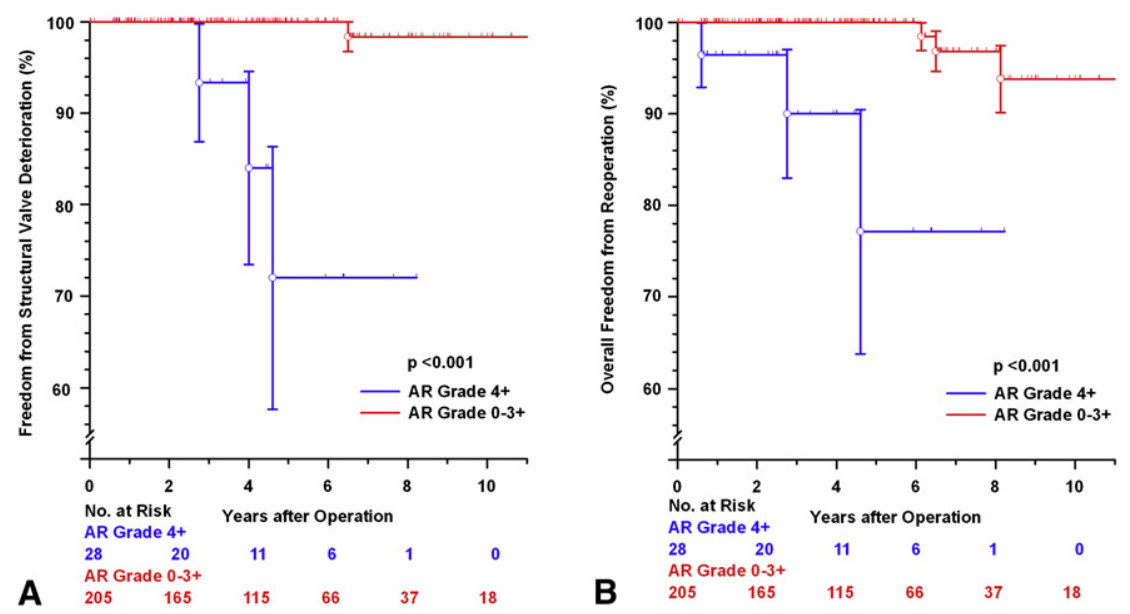

FIGURE E3. A, Freedom from structural valve deterioration comparing patients with 4+aortic regurgitation $(A R)$ preoperatively and remainder of patients. B, Freedom from reoperation on aortic root comparing patients with $4+$ aortic regurgitation preoperatively and remainder of patients. Vertical bars represent \pm 1 standard error.

TABLE E1. Early postoperative complications among 233 Tirone David valve-sparing aortic root replacement patients

\begin{tabular}{lc}
\hline \multicolumn{1}{c}{ Variable } & Value \\
\hline In-hospital mortality (30 d) & $2(0.9)$ \\
Mediastinal re-exploration because of bleeding & $8(3)$ \\
Cardiac complications & \\
$\quad$ Acute myocardial infarction & $1(0.4)$ \\
Atrial fibrillation & $29(12)$ \\
Permanent pacemaker & $8(3)$ \\
Stroke & $2(0.9)$ \\
Acute renal dysfunction & 0 \\
Length of hospital stay (d) & \\
Median & 6 \\
IQR & $5-7$ \\
\hline Da
\end{tabular}

Data presented as n (\%) or median and IQR. IQR, Interquartile range.
TABLE E2. Complications in 231 surviving Tirone David valvesparing aortic root replacement patients

\begin{tabular}{lc}
\hline \multicolumn{1}{c}{ Variable } & $\mathbf{n}(\%)$ \\
\hline Superficial wound infection & $2(0.9)$ \\
Deep sternal infection & $1(0.4)$ \\
Late mortality & $2(0.9)$ \\
Thromboembolism & $3(1.3)$ \\
TIA & $2(0.9)$ \\
Stroke & $1(0.4)$ \\
Bleeding events & 0 \\
Endocarditis requiring operative management & $2(0.9)$ \\
Acute type B aortic dissection & $6(2.6)$ \\
Conservative therapy & $6(2.6)$ \\
Operative treatment & 0 \\
Reoperation for structural valve deterioration & $3(1.3)$ \\
AVR & $3(1.3)$ \\
Repeat repair & 0 \\
Late pacemaker & $3(1.3)$ \\
Third-degree AV block & $3(1.3)$ \\
\hline$A V$, Atrioventricular; AVR, aortic valve replacement; TIA, transient ischemic attack. & \\
\end{tabular}


TABLE E3. Clinical characteristics of 6 patients with Stanford type B dissection

\begin{tabular}{|c|c|c|c|c|c|c|}
\hline \multirow[b]{2}{*}{ Variable } & \multicolumn{6}{|c|}{ Pt. no. } \\
\hline & 1 & 2 & 3 & 4 & 5 & 6 \\
\hline Age at operation $(y)$ & 48 & 32 & 32 & 36 & 19 & 26 \\
\hline Gender & $\mathrm{F}$ & M & $\mathrm{F}$ & $\mathrm{F}$ & $\mathrm{F}$ & $\mathrm{F}$ \\
\hline CTD & MFS & MFS & MFS & MFS & MFS & LDS \\
\hline Operation type & TD-I & TD-V & TD-V-S-Mod & TD-V-S-Mod & TD-V-S-Mod & TD-V-S-Mod \\
\hline Graft diameter $(\mathrm{cm})$ & 26 & 32 & 34 & 30 & 30 & 30 \\
\hline Proximal or annular end & 26 & 27 & 25 & 25 & 27 & 25 \\
\hline Distal & 26 & 32 & 20 & 22 & 20 & 20 \\
\hline Aortic valve type & TAV & TAV & TAV & BAV & TAV & TAV \\
\hline Preoperative AR & +3 & 0 & +3 & 0 & +3 & 0 \\
\hline Postoperative AR & +1 & +1 & +1 & +1 & +1 & 0 \\
\hline Interval to dissection (mo) & 103 & 100 & 34 & 42 & 19 & 23 \\
\hline
\end{tabular}

$A R$, Aortic regurgitation; $B A V$, bicuspid aortic valve; $C T D$, connective tissue disorder; $F$, female; $L D S$, Loeys-Dietz syndrome; $M$, male; $M F S$, Marfan syndrome; Pt. no., patient number; $T A V$, tricuspid aortic valve; TD-I, Tirone David-I valve-sparing aortic root replacement; TD-V, Tirone David-V valve-sparing aortic root replacement; TD-V-S-Mod, Tirone David-V-Stanford modification valve-sparing aortic root replacement.

TABLE E4. Clinical characteristics of 4 patients with structural valve deterioration after Tirone David valve-sparing aortic root replacement

\begin{tabular}{|c|c|c|c|c|}
\hline \multirow[b]{2}{*}{ Variable } & \multicolumn{4}{|c|}{ Pt. no. } \\
\hline & 1 & 2 & 3 & 4 \\
\hline Age at operation $(y)$ & 44 & 18 & 27 & 11 \\
\hline Gender & Female & Male & Male & Male \\
\hline CTD & None & MFS & None & MFS \\
\hline Preoperative AR & None & Severe & Severe & Severe \\
\hline V-SARR procedure type & TD-I & TD-V-S-Mod & TD-V-S-Mod & TD-V-S-Mod \\
\hline Aortic valve type & TAV & TAV & $\mathrm{BAV}, 1 / \mathrm{L}-\mathrm{R} / \mathrm{r}$ & TAV \\
\hline Valve repair & No & No & Yes; Gore-Tex neochord & Yes; cusp FM shortening \\
\hline Postoperative AR & None & Mild & Mild & None \\
\hline AR before reoperation & Severe & Severe & Severe & Severe \\
\hline Interval to reoperation $(\mathrm{mo})$ & 77 & 55 & 33 & NA* \\
\hline
\end{tabular}

$\overline{A R}$, Aortic regurgitation; $B A V$, bicuspid aortic valve; $C T D$, connective tissue disorder; $F M$, free margin; $M F S$, Marfan syndrome; Pt. no., patient number; TAV, tricuspid aortic valve; $T D$ - , Tirone David-I valve-sparing aortic root replacement; $T D-V$-S-Mod, Tirone David-V-Stanford modification valve-sparing aortic root replacement. *Patient 4 underwent aortic valve replacement after end of the study closing interval and 53 months after valve-sparing aortic root replacement and mitral valve repair. 
TABLE E5. Overview of variables tested in Cox proportional hazard regression analysis $(n=233)$

\begin{tabular}{lclc}
\hline \multicolumn{1}{c}{ Variable } & HR & \multicolumn{1}{c}{$\mathbf{9 5} \% \mathbf{C I}$} & $\boldsymbol{P}$ value \\
\hline Age $(\mathrm{y})$ & 0.902 & $0.845-0.962$ & .002 \\
Gender & 1.963 & $0.393-9.794$ & .411 \\
Weight $(\mathrm{kg})$ & 1.015 & $0.967-1.066$ & .550 \\
Height $(\mathrm{m})$ & 0.944 & $0.887-1.005$ & .073 \\
STBSA $\left(\mathrm{m}^{2}\right)$ & 0.818 & $0.0216-30.903$ & .915 \\
LVEF $(\%)$ & 0.953 & $0.871-1.042$ & .289 \\
MFS or other CTD & 3.506 & $0.567-21.675$ & .177 \\
BAV & 6.426 & $0.747-55.318$ & .090 \\
Aortic cusp repair & 0.686 & $0.166-2.832$ & .603 \\
Arch replacement & 12.377 & $1.289-118.879$ & .029 \\
CPB time (min) & 1.000 & $0.984-1.016$ & .994 \\
Crossclamp time (min) & 1.002 & $0.978-1.027$ & .879 \\
AR $>$ 2+ preoperative & 6.038 & $1.361-26.795$ & .018 \\
\hline
\end{tabular}

For this analysis, we constructed a composite endpoint, but only 14 total adverse events occurred ( 4 deaths [2 in-hospital and 2 late], 4 SVD, 3 reoperations [not due to SVD, 2 caused by endocarditis], 1 stroke, and 2 TIA); small number of events made Cox model unstable, providing unreliable results without clinical relevance, as shown by extremely wide $95 \%$ confidence intervals. $A R$, Aortic regurgitation; $B A V$, bicuspid aortic valve; $C I$, confidence interval; $C P B$, cardiopulmonary bypass; $C T D$, connective tissue disorder; $H R$, hazard ratio; $L V E F$, left ventricular ejection fraction; MFS, Marfan syndrome. 